\title{
Gene functionalities and genome structure in Bathycoccus prasinos reflect cellular specializations at the base of the green lineage
}

\author{
Hervé Moreau ${ }^{1,2^{*}}$, Bram Verhelst ${ }^{3,4}$, Arnaud Couloux ${ }^{5}$, Evelyne Derelle ${ }^{1,2}$, Stephane Rombauts ${ }^{3,4}$, Nigel Grimsley ${ }^{1,2}$, \\ Michiel Van Bel ${ }^{3,4}$, Julie Poulain ${ }^{5}$, Michaël Katinka ${ }^{5}$, Martin F Hohmann-Marriott ${ }^{6}$, Gwenael Piganeau ${ }^{1,2}$, \\ Pierre Rouzé $e^{3,4}$, Corinne Da Silva ${ }^{5}$, Patrick Wincker ${ }^{5+}$, Yves Van de Peer ${ }^{3,4+}$ and Klaas Vandepoele $e^{3,4}$
}

\begin{abstract}
Background: Bathycoccus prasinos is an extremely small cosmopolitan marine green alga whose cells are covered with intricate spider's web patterned scales that develop within the Golgi cisternae before their transport to the cell surface. The objective of this work is to sequence and analyze its genome, and to present a comparative analysis with other known genomes of the green lineage.

Research: Its small genome of $15 \mathrm{Mb}$ consists of 19 chromosomes and lacks transposons. Although $70 \%$ of all B. prasinos genes share similarities with other Viridiplantae genes, up to 428 genes were probably acquired by horizontal gene transfer, mainly from other eukaryotes. Two chromosomes, one big and one small, are atypical, an unusual synapomorphic feature within the Mamiellales. Genes on these atypical outlier chromosomes show lower GC content and a significant fraction of putative horizontal gene transfer genes. Whereas the small outlier chromosome lacks colinearity with other Mamiellales and contains many unknown genes without homologs in other species, the big outlier shows a higher intron content, increased expression levels and a unique clustering pattern of housekeeping functionalities. Four gene families are highly expanded in B. prasinos, including sialyltransferases, sialidases, ankyrin repeats and zinc ion-binding genes, and we hypothesize that these genes are associated with the process of scale biogenesis.
\end{abstract}

Conclusion: The minimal genomes of the Mamiellophyceae provide a baseline for evolutionary and functional analyses of metabolic processes in green plants.

\section{Background}

Marine phytoplankton is responsible for about half of the photosynthetic activity on the planet [1], the second half being carried out by terrestrial plants. Two major traits differentiate these two classes of organisms. First, phytoplankton is essentially composed of unicellular organisms that have a high turnover; whereas terrestrial plants are renewed, on average, once every 9 years, the global phytoplankton population is replaced approximately every week [1]. Second, while photosynthesis is confined to specific organs of plants, often only a minor component of the plant biomass, in phytoplankton, photosynthesis

\footnotetext{
* Correspondence: herve.moreau@obs-banyuls.fr

† Contributed equally

${ }^{1}$ CNRS, UMR 7232, Observatoire Océanologique, Banyuls-sur-Mer, France Full list of author information is available at the end of the article
}

essentially takes place in each cell. Phytoplankton populations are thus highly dynamic and may be able to adapt rapidly to changing environments. Even so, a global decline of photosynthetic micro-organisms over the past century has recently been reported [2], motivating research aimed at better understanding the global diversity of phytoplankton and how these species adapt to changing marine environment.

Phytoplankton is usually pragmatically classified according to size, from pico- (below $3 \mu \mathrm{m}$ ), nano- (3 to $8 \mu \mathrm{m})$ to micro-algae (above 5 to $8 \mu \mathrm{m}$ ), although these categories have no evolutionary significance. The eukaryotic fraction of picophytoplankton accounts for a modest part of the oceanic biomass, but nevertheless contributes an important part to primary production in many oceanic waters $[3,4]$. Among these picoeukaryotes, environmental diversity 
studies based on ribosomal gene sequences showed that small green algae, and notably the three genera Bathycoccus, Micromonas and Ostreococcus, are distributed worldwide and are numerically important in coastal areas. These three genera are characterized by their small size (1 to $2 \mu \mathrm{m}$ ), their rudimentary cellular organization (one mitochondrion and one chloroplast) and their small genomes (from 13 to $22 \mathrm{Mb}$ ). Micromonas [5] is a naked cell with one long flagellum whereas the two other genera are nonmotile. Ostreococcus [6,7] is naked whereas Bathycoccus [8] is covered with scales. The complete genome sequences of two Micromonas [9], two Ostreococcus [10,11] and a lowlight adapted strain of Ostreococcus (strain RCC809, available on the Joint Genome Institute web site) have been analyzed. The three genera belong to the order Mamiellales, in the class Mamiellophyceae [12,13], a monophyletic group in the phylum Chlorophyta. The ancestors of these micro-organisms emerged at the base of the green lineage and knowledge about them provides a baseline for exploring the evolution of this lineage, which also gave rise to terrestrial plants. Given their small cellular and genome sizes, they may reveal the 'bare limits' of life as a free-living photosynthetic eukaryotes, thus presenting a simple organization with very little non-coding sequences [14].

Here we report the analysis of the genome of one Mediterranean strain belonging to the genus Bathycoccus and its comparison with Mamiellales and other green algae, allowing a survey of the genome organization at the base of the green lineage. Although Bathycoccus was initially isolated from deep water (100 meters) [8], it has been frequently reported in various marine environments and seems an important component of the picoeukaryote compartment [15-18]. The availability of this genome, coupled to the development of new sequencing possibilities for metagenomes $[19,20]$ from various marine environments, opens the way for comparative studies and to a better understanding of the adaptations of this organism to its environment(s).

\section{Results and discussion}

\section{Characterization and phylogenetic position of the Bathycoccus prasinos RCC1105 strain}

We isolated the Bathycoccus prasinos strain RCC1105 from a seawater sample from Banyuls' bay collected in January 2006. Contrary to the type strain described as Bathycoccus prasinos [8], which was isolated at a depth of 100 meters, RCC1105 was isolated from surface water (5 m). The strain RCC1105 has a typical Bathycoccus morphology with scales covering the cell (Figure 1) and we confirmed its taxonomic affiliation by PCR amplification of its $18 \mathrm{~S}$ ribosomal gene. The complete genome of RCC1105 revealed two unlinked identical copies of the rDNA genes. Unlike the two previously reported $B$. prasinos isolates $[8,21]$, these two ribosomal $18 \mathrm{~S}$ genes were found to harbor an identical 433 bp long group I intron starting at position 551. Apart from this, the nucleotide sequence was strictly identical to the reference strain (GenBank: AY425315, FN562453). Self-splicing group I introns are widespread in nature, and have been recorded in the $18 \mathrm{~S}$ rDNA of several other protists [22], including some within the green lineage, but, so far, not within the Mamiellales. All four Bathycoccus strains isolated from the Mediterranean bear this intron located exactly at the same splicing site. Phylogenetic analysis based on this small ribosomal subunit and on the internal transcribed spacer (ITS) confirmed that, in contrast to the two other Mamiellales' genera Micromonas and Ostreococcus, all Bathycoccus strains isolated to date comprise only one clade [12,13]. To confirm the phylogenetic position of Bathycoccus within the Mamiellales, we concatenated a set of 154 single-copy genes conserved in 13 species, including plants, and aligned them over 35,431 amino acids to construct a maximum likelihood phylogenetic species tree (Figure S1 in Additional file 1, and Additional files 2 and 3). The phylogeny obtained was wellsupported and showed that the genus Bathycoccus is closer to Ostreococcus than to Micromonas.

\section{Global characteristics of the Bathycoccus genome}

The global characteristics of the Bathycoccus genome are similar to those observed in other Mamiellales except for its significantly lower GC content [17] (Table 1; Figures S2 and S3 in Additional file 1). The global genome size, measured by both pulsed field gel electrophoresis (Figure 2a) and sequencing, is intermediate (15 Mb) between Ostreococcus (12 to $13 \mathrm{Mb}$ ) and Micromonas (21 to $22 \mathrm{Mb}$ ), also reflecting an intermediate number of genes (Table 1; Table S1 in Additional file 1). Both sequencing and pulsed field gel electrophoresis also showed the genome to comprise 19 chromosomes, a number close to that found in other Mamiellales, and in other green algae despite the variation in genome size (Table 1; Table S1 in Additional file 1). The $15 \mathrm{Mb}$ genome was sequenced at 22-fold coverage using a whole-genome shotgun sequencing approach, resulting in 126 contigs ranging from 3 to $1,353 \mathrm{~kb}$. According to blast analysis, the 102 smallest of these contigs were bacterial contaminations, whereas the 24 remaining bigger contigs were part of the Bathycoccus genome (22 nuclear, 1 chloroplastic and 1 mitochondrial contig). Among the 22 nuclear contigs, six could be joined two by two, giving 19 scaffolds corresponding to 19 chromosomes observed by pulse field electrophoresis (Figure S3 in Additional file 1; Table S1 in Additional file 1; Additional file 4). Using intrinsic and extrinsic information, we predicted 7,847 genes in the nuclear genome (see Materials and methods), giving a high gene density similar to other Mamiellales. The validity of a majority of predicted genes was supported either by ESTs (approximately 46\%) or by 


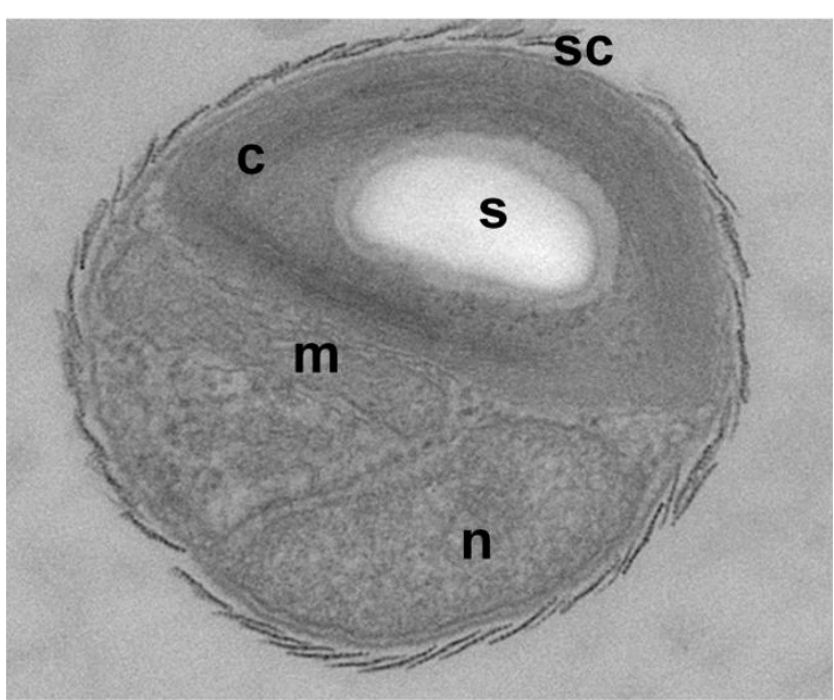

Figure 1 Morphology of the Bathycoccus prasinos RCC1105 strain. Morphological characterization of the Bathycoccus RCC1105 strain: EM picture of an exponentially growing Bathycoccus RCC1105 cell. Abbreviations: c, chloroplast; n, nucleus; s, starch granule; Sc, scale covering the surface of the cell.

protein similarity (approximately 85\%), and approximately $15 \%$ of them contain introns. Very few repeat sequences were found and no known or new transposable elements were detected (Table S1 in Additional file 1). The synteny observed between the chromosomes of Ostreococcus and Bathycoccus (Figure 2b; Figure S4 in Additional file 1) shows that the genome organization is globally better conserved between these two genera than with the genus Micromonas, in agreement with the phylogenetic analysis.

Based on the annotated gene sets of different land plants and green algae, sequence similarity searches were performed to group homologous genes into families (a family being defined as a set of two or more homologous genes; see Materials and methods). Subsequently, pan and core genome plots were built to quantify the number of shared and unique genes and families between different species (Figure S5 in Additional file 1). Comparing the set of core genes between different algal groups reveals that the smaller genome sizes of Mamiellales, as well as the lower number of genes, correspond both with the decrease of the average number of genes per family and with the number of families conserved within a specific clade. For example, whereas the number of gene families shared between all land plants, Chlamydomonales, and Trebouxiophyceae is 2,692, this number drops to 1,959 when including all Mamiellales species. Similarly, based on a set of core gene families conserved in both land plants and algae, the average gene family size is smaller for Mamiellales compared to Trebouxiophyceae or Chlamydomonales (average of $1.63,1.78$ and 1.93 genes per family, respectively). More than 500 gene families were found that were conserved between land plants and green algae but that were lost in all Mamiellales species (Figure S6 in Additional file 1). These families were enriched for functions related to zinc ion-binding and transport (ten families), UDP-glucosyltransferase activity (six families), vitamin ion binding (eight families) and sucrose and fatty acid metabolism (eight families) (Table S2 in Additional file 1). Although

Table 1 Nuclear genome characteristics of green algae

\begin{tabular}{|c|c|c|c|c|c|}
\hline Family & Species & Genome size (Mb) & $\mathrm{G}+\mathrm{C}(\%)$ & Chromosome number & Gene number \\
\hline Prasinophyceae & Bathycoccus sp. RCC1105 & 151 & 48 & 19 & 7,847 \\
\hline Prasinophyceae & Micromonas sp. RCC299 & 20.9 & 64 & 17 & 10,286 \\
\hline Prasinophyceae & Micromonas sp. CCMP1545 & 21.9 & 65 & 19 & 10,587 \\
\hline Prasinophyceae & Ostreococcus lucimarinus clade A & 13.2 & 60 & 21 & 7,805 \\
\hline Prasinophyceae & Ostreococcus sp. RCC809 clade B & 13.3 & 60 & 20 & 7,492 \\
\hline Prasinophyceae & Ostreococcus tauri clade C & 12.6 & 59 & 20 & 8,116 \\
\hline Trebouxiophyceae & Chlorella sp. NC64A & 46 & 67 & 12 & 9,791 \\
\hline Chlorophyceae & Chlamydomonas reinhardtii & 121 & 64 & 17 & 15,143 \\
\hline Chlorophyceae & Volvox carterii & 138 & 56 & 14 & 14,520 \\
\hline
\end{tabular}

Data from $[9,10,24,68,69]$. 
A

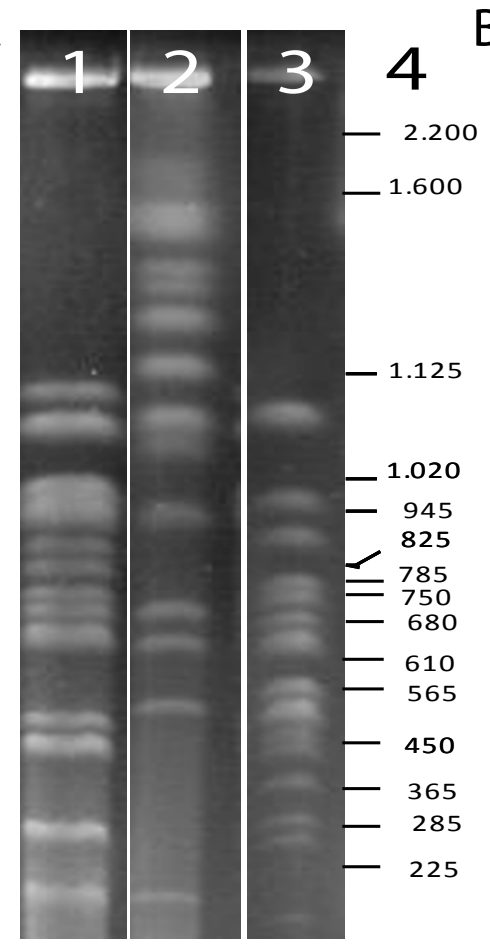

B

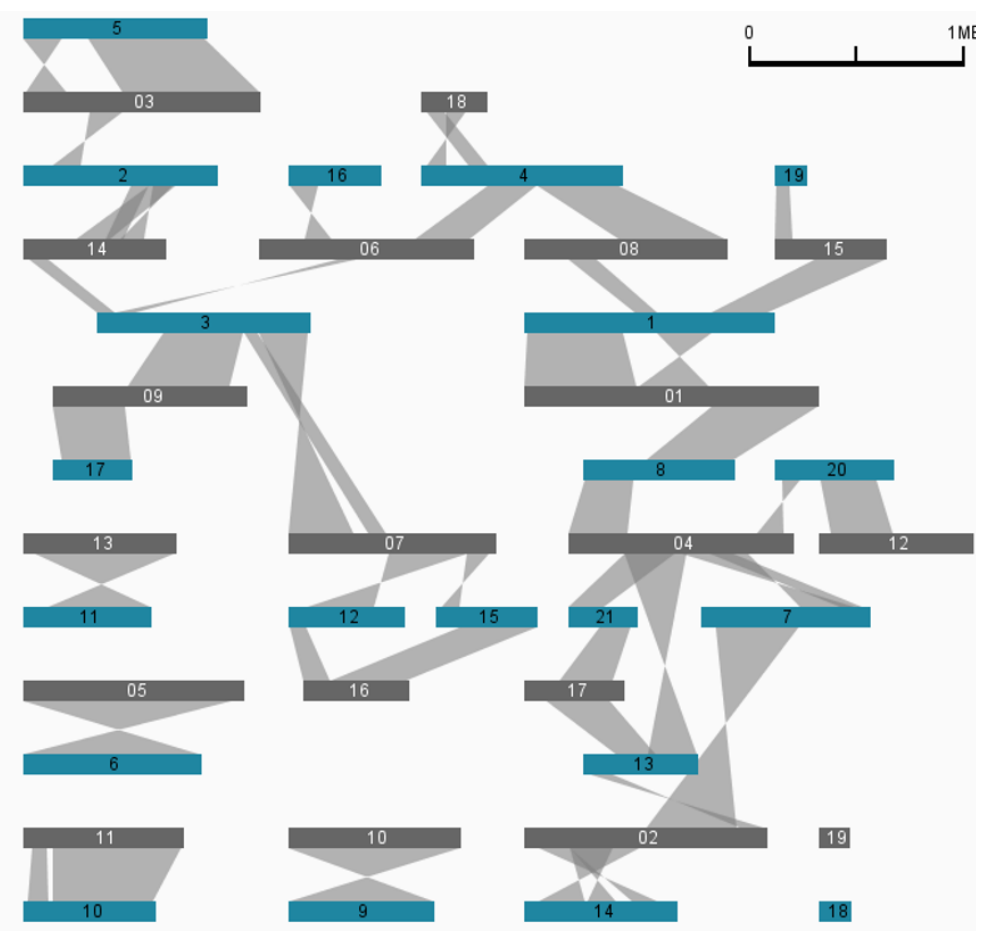

Figure 2 Genome organization of the Bathycoccus prasinos RCC1105 strain. (a) Pulse field electrophoresis of the genomes of Bathycoccus prasinos RCC1105 (lane 1), Micromonas pussilla (lane 2) and Ostreococcus tauri (lane 3) DNA fragment length based on the chromosomes of Saccharomyces cerevisiae (lane 4). (b) Synteny between Ostreococcus lucimarinus (blue) and Bathycoccus prasinos RCC1105 (grey) genomes.

this pattern suggests a reduction of the functional gene repertoire, we also found more than 400 gene families that are specific to Mamiellales and found in all Mamiellales species. Whereas many of these Mamiellales-specific genes have unknown functions, three families related to drug transport and ten families including genes related to zinc ion binding were found (Table S2 in Additional file 1). Although rapid sequence evolution can interfere with the accurate detection of homologs using similarity searches, the observed pattern indicates a high turnover of zinc ion binding-related genes.

Biological role and evolution of the big and small outlier chromosomes in Bathycoccus and in the Mamiellales

Despite the low average GC content (48\%; Table 1) of the Bathycoccus genome compared to other members of the Mamiellales (over 59\%; Table 1), two outlier chromosomes were found, one 'big' (chromosome 14) and one 'small' (chromosome 19), with lower GC content (42\%) compared to the rest of the genome (Table 2; Figure S7 in Additional file 1). This kind of organization was previously reported in Micromonas and Ostreococcus [9-11,23] and thus is a characteristic of all Mamiellales that have been sequenced so far. In all species, the atypical genomic features for the 'big' outlier chromosomes (BOCs) are restricted to a sub-region (referred to as BOC1) of the complete chromosome, whereas the whole length of the 'small' outlier chromosome (SOC) shows low GC content (Figure S7 in Additional file 1). However, although a $\mathrm{BOC}$ region was found for the 'low-light' Ostreococcus sp. RCC809 genome, which is available on the Joint Genome Institute website (unpublished), no clear SOC could be identified (Additional file 1). Whether this observation is biologically correct or the consequence of the applied sequencing approach, read filtering, or genome assembly remains currently unclear. Similar outlier chromosomes have not been found in other green algae such as Chlamydomonas, Volvox or Chlorella. In Chlorella low GC chromosome regions were reported [24], but these were, in contrast to those in the Mamiellales, scattered throughout different chromosomes. Outlier chromosomes are highly diverged in terms of gene content. Whereas most Bathycoccus chromosomes share, to some extent, a conserved genome organization with the other Mamiellales, both BOC1 (217 annotated genes) and SOC (72 annotated genes) lack colinearity (Figure 3), and this pattern is largely conserved between the outliers of the three genera. Many BOC1 genes share orthologs with other Mamiellales while SOC comprises mainly unknown, species-specific genes with few introns (26\% of the SOC proteins have Gene Ontology functional annotation versus $71 \%$ for BOC1 genes and $44 \%$ for the rest of the genome; Figure 3; Figure S8 in Additional file 1). Additionally, 
Table 2 Characteristics of the small outlier chromosomes for Bathycoccus and one Micromonas and one Ostreococcus species

\begin{tabular}{|c|c|c|c|c|c|c|c|c|c|}
\hline Species & $\begin{array}{l}\text { Chromosome } \\
\text { number }\end{array}$ & $\begin{array}{l}\text { Size } \\
\text { (kb) }\end{array}$ & $\begin{array}{l}\mathrm{GC} \\
(\%)\end{array}$ & $\begin{array}{c}\text { ORF } \\
\text { number }\end{array}$ & $\begin{array}{l}\text { Gene densities } \\
\text { (bp/gene) }\end{array}$ & $\begin{array}{l}\text { Identified } \\
\text { genes }\end{array}$ & $\begin{array}{c}\text { Sugar } \\
\text { metabolism }\end{array}$ & $\begin{array}{l}\text { Methylation } \\
\text { enzymes }\end{array}$ & $\begin{array}{l}\text { Other } \\
\text { function }\end{array}$ \\
\hline Bathycoccus sp. & 19 & 146 & 42 & 72 & 2,031 & $34(47 \%)$ & 17 (24\%) & $7(10 \%)$ & $4(6 \%)$ \\
\hline $\begin{array}{l}\text { Ostreococcus } \\
\text { lucimarinus }\end{array}$ & 18 & 149 & 53 & 78 & 1,915 & $32(41 \%)$ & $16(21 \%)$ & $5(6 \%)$ & $11(14 \%)$ \\
\hline $\begin{array}{l}\text { Micromonas sp. } \\
\text { RCC } 299\end{array}$ & 17 & 215 & 51 & 80 & 2,684 & $30(38 \%)$ & $14(18 \%)$ & 7 (9\%) & $9(11 \%)$ \\
\hline
\end{tabular}

ORF, open reading frame.

phylogenetic estimations of the proportions of genes lacking plant orthologs yielded 75\% (54/72) for SOC, 16\% for BOC1 and 25\% for normal chromosomal regions.

\section{The big outlier chromosome in Bathycoccus}

The size of the Bathycoccus BOC is 663,424 bp. Fifty-two and seventy-eight percent of the Bathycoccus BOC1 genes having orthologs in other species were also located in the BOC in Micromonas and Ostreococus, respectively (Figure 4). In contrast, the locations of 29 BOC1 singlecopy conserved gene markers (that is, genes having orthologs and located in BOC1 in all Mamiellales; Table S3 in Additional file 1) were scattered throughout the genomes in Chlamydomonas, Volvox and Chlorella, revealing that, despite the absence of colinearity, the clustering of the BOC1 genes is conserved and unique to the Mamiellales. These data suggest that BOC1 is a conserved genome property that was present in the last common ancestor of the Mamiellales. Genes located in the $\mathrm{BOC} 1$ region are over-represented in basic housekeeping functions like primary metabolism, gene expression, photosynthesis and protein transport (Figure S8 in Additional file 1; Table S3 in Additional file 1). To identify genomic features that are specific for the BOC1 region, the C-hunter tool (see Materials and methods) was applied to detect significant physical clustering of highly expressed genes and intron-containing genes on the different chromosomes (Table S4 in Additional file 1). C-hunter analysis revealed that the $\mathrm{BOC} 1$ region shows, in all species, a significant over-representation of EST-supported genes. Globally, $75 \%$ of all BOC1 Bathycoccus genes are EST supported versus $47 \%$ for non-BOC1 genes (Figure 3). After correcting for the overall 1.6-fold higher expression of $\mathrm{BOC} 1$ genes, $\mathrm{BOC} 1$ genes related to chromatin assembly, protein transport activity and signal transduction showed increased expression levels (Figure S8 in Additional file 1). To verify whether the high expression is a property of the low $\mathrm{GC}$ genomic $\mathrm{BOC} 1$ region (for example, due to a more open chromatin structure [25]), we checked the expression level of the genes on the other low GC chromosome, SOC. We found that SOC genes had no difference in expression level compared to the genes on the 17 other chromosomes. We further investigated whether this higher expression rate is an intrinsic property of the genes themselves, and estimated the expression levels for orthologs in Chlamydomonas, Volvox and Coccomyxa sp. C-169 (Figure S9A in Additional file 1). In all three species, BOC1 orthologs were also more highly expressed than other genes in the genome, suggesting that the higher expression of $\mathrm{BOC} 1$ genes in the Mamiellales is related to their function. Alternatively, this pattern might also be due to the global positive correlation, observed for all Mamiellales, between intron content and expression (Figure S9B in Additional file 1). Although the high expression of basic housekeeping BOC1 gene functions might yield increased metabolic rates and overall growth, it is not clear whether the physical clustering of BOC1 genes in the Mammiellophyceae lineage is based on adaptive gene relocation or constrained ancestral location [26].

The BOC1 region also displays structural specificities that are absent in the rest of the genome. Besides its low $\mathrm{GC}$ content, genes in the BOC1 region are split by many small (40 to $65 \mathrm{bp}$ ) AT-rich introns [10,11]. This feature is present in all of the sequenced Mamiellales genomes (Figure S10 in Additional file 1) and absent from the genomes of other green algae (Figure S10 in Additional file 1). There is no universal RNA-fold for these introns and no conserved sequence motifs (for example, branch points, splice sites) could be detected. Although the only intrinsic indication from their DNA sequences that they are introns comes from their AT-richness relative to the surrounding $\mathrm{GC}$ rich exons, their existence is clear from EST data. Consequently, the $\mathrm{BOC} 1$ region includes a high proportion of multiple exon genes, a feature absent in the rest of the genome (Table S2 in Additional file 1). In Bathycoccus, 103 of the 214 BOC1 genes harbor 330 introns, an intron content tenfold higher than in the rest of the genome (average of 1.54 and 0.15 introns per BOC1 and nonBOC1 gene, respectively).

In conclusion, the $\mathrm{BOC} 1$ region in the Mamiellales has unique structural characteristics: it represent one contiguous low(er) GC content region in the chromosome, flanked by two high(er) GC content regions at the extremities and carries between 193 and 633 genes depending on the species examined. The gene order within the region shows little colinearity between species and it 


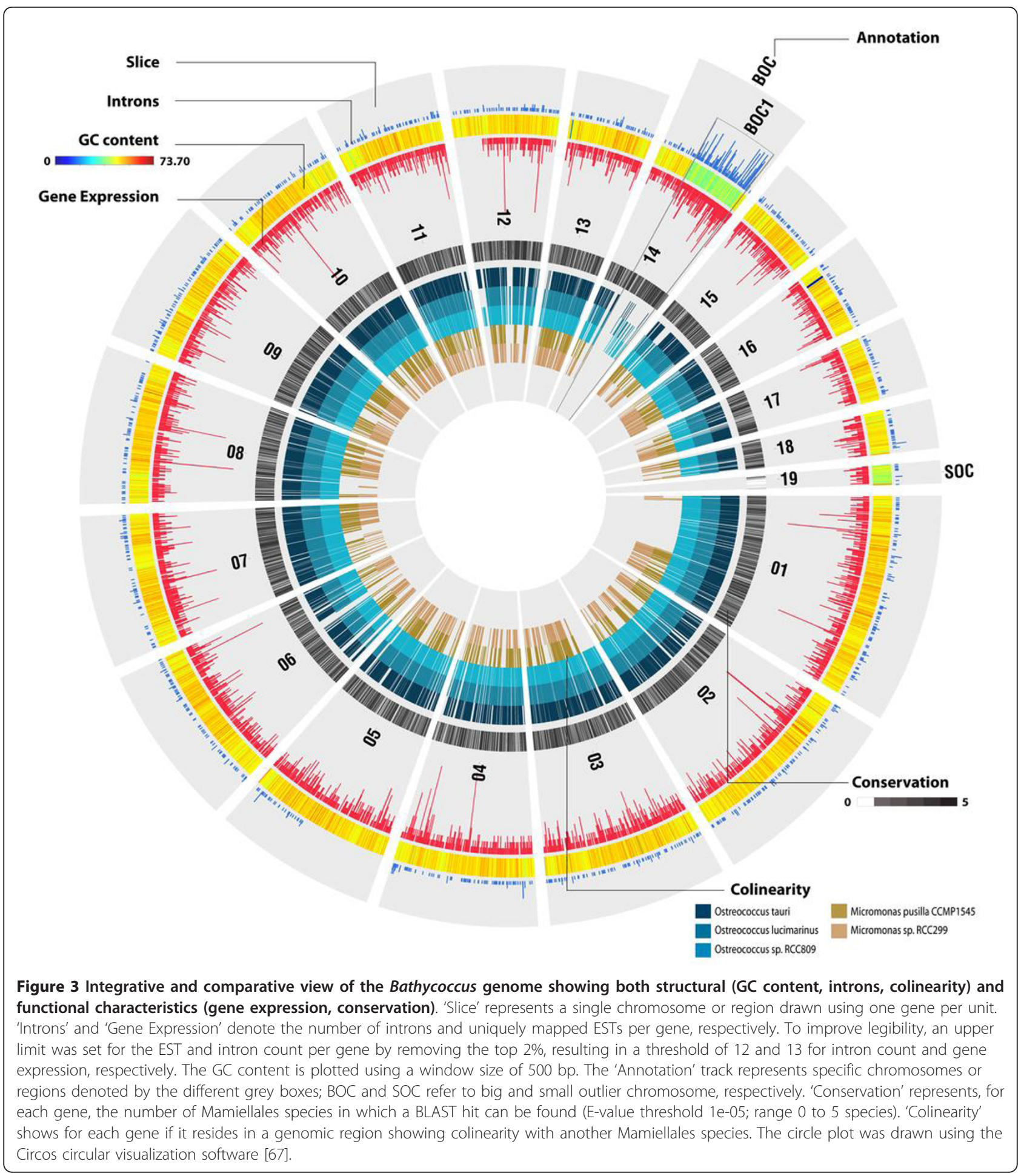

encodes a high proportion of often vital housekeeping genes with elevated expression levels clustered together in a pattern unique to the Mamiellales (Figure 4). The biological reason for the existence of this region remains obscure, although its structural characteristics (shuffling of genes, small introns, low GC content) concur with the hypothesis that it may be a sex or species-barrier chromosome $[27,28]$.

The small outlier chromosome in Bathycoccus

The size of the Bathycoccus small outlier chromosome is 146,238 bp. compared to around $150 \mathrm{~kb}$ in Ostreococcus 


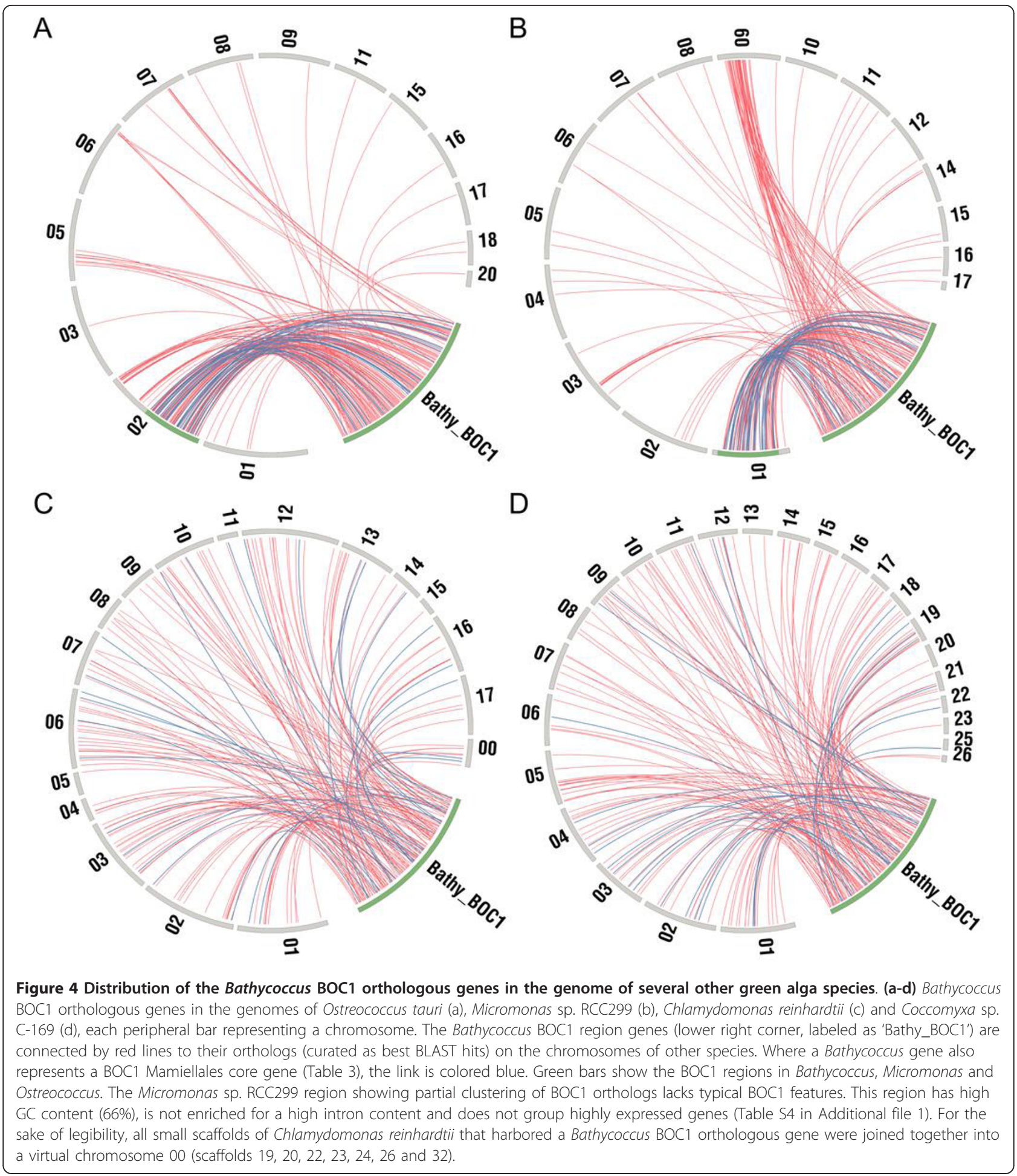

lucimarinus and 200 to $250 \mathrm{~kb}$ in Micromonas. The SOC average gene density in $B$. prasinos is slightly lower than that observed in the other chromosomes (72 genes with an average of $2.0 \mathrm{~kb}$ per gene in SOC compared to $1.7 \mathrm{~kb}$ per gene in the global genome), with a similar expression level based on EST counts. Only $44 \%$ of the genes in SOC have a potentially identified function compared to $77 \%$ in other chromosomes. Furthermore, up to $75 \%$ of the SOC genes have no known plant orthologs, in sharp contrast to most other chromosomes, where most genes share green lineage descent. Last but not least, in Bathycoccus, 24 of the 34 SOC genes having 
an identified function group in two categories. The first group encodes enzymes involved in metabolism of glycoconjugates (17 genes), mainly glycosyltransferase (12 genes), and the second is related to methyl transferases (7 genes). These features are globally similar in the other known Mamiellales SOCs, where the same two dominant gene functions were found (Table 2). However, despite their common function, no synteny and almost no orthologous relationships could be established between the SOCs of the different Mamiellales' species, suggesting a more functional convergence than a common phylogenetic origin. To explain the presence of such genes in SOCs, an alien origin of these chromosomes was proposed, which could have yielded some selective advantages in cell surface processes, potentially related, for example, to defense against pathogens or other environmental interactions [10]. However, since SOCs and BOCs have now been found in all sequenced mamiellophycean genomes, it is likely that their lower GC composition, higher proportion of specific genes and higher evolution rates $[9,29]$ are being maintained by the same evolutionary pressure in all of these species. Interestingly, a paper on the cyanobacteria Prochlorococcus describes how variable genomic islands showing similar characteristics to those found in SOCs (low number of orthologs, a high level of horizontal gene transfer (HGT) and a high fraction of sugar-modifying enzymes, methyl transferases and membrane associated proteins) are involved in resistance to viruses [30]. The viral resistance determined by these genomic islands induced a fitness cost measured either by a reduced growth rate and/or a more rapid infection by other viruses. The three genera Bathycoccus, Micromonas and Ostreococcus are the microalgae tested, which are among the most attacked by viruses [31], and viral resistance phenomena showing similar characteristics to what is reported for Prochlorococcus (reduced growth rate and higher infection rate by other viruses) have been reported to occur frequently [32]. It is tempting to link this unusual high viral sensitivity and the ability to develop rapid and frequent resistance to these attacks to the presence of SOCs. Interestingly, two other Mamiellales species (Mamiella sp. or Mantoniella squamata) were tested recently and did not show this high viral sensitivity (N Simon, personal communication). It can be predicted that if our hypothesis on the link between SOC and viral hypersensitivity/resistance is correct, these species should not present a SOC-like structure in their genome.

\section{Phylogenomics suggests many horizontal gene transfers}

Based on the observation that no plant homologs could be found for many annotated Bathycoccus genes, a systematic analysis was performed to unravel their origin. Since plain sequence similarity search strategies are insufficient to reliably trace a gene's evolutionary history [33,34], a twostep comparative approach was applied to identify putative HGT events. After comparing each Bathycoccus protein sequence against the National Center for Biotechnology Information (NCBI) protein database, 6,550 phylogenetic trees were constructed and conflicts between the gene and organism phylogeny were determined. Whereas clustering patterns where the nearest neighbor in the tree corresponds with a homolog from a species outside the plant lineage were scored as HGT, in some cases ancestral gene duplication followed by differential gene loss or artifacts of phylogenetic reconstruction methods due to unusual modes of protein evolution could yield misleading results [35]. There were 428 genes (6\%) that clustered with a homologous gene from a species outside the green lineage, whereas the remaining genes grouped with Viridiplantae genes $(70 \%)$ or did not show any significant similarity. Among the 428 putative non-Viridiplantae genes, 80\% were of non-green eukaryotic origin while $17 \%$ were bacterial orthologs (Figure 5a). For the 354 non-green eukaryotic genes, a high proportion came from Metazoa and Stramenopiles ( $42 \%$ and $28 \%$, respectively). Gene Ontology enrichment analysis showed that around $50 \%$ of the nonViridiplantae genes (including prokaryotic genes) were involved in metabolism. Focusing on the most enriched categories revealed genes involved in zinc ion binding (61, 6-fold enrichment), sialyltransferase activity (27, 12-fold enrichment), glycosylation (27, 11-fold enrichment) and ankyrin repeats (5-fold enrichment) (these observations are discussed further in the following section). Application of conservative selection criteria (retaining only phylogenetic trees with bootstrap support $>90 \%$ and more than $50 \%$ protein alignment coverage) yielded 79 genes with non-plant nearest neighbors (Table S5 in Additional file 1), which we propose might originate from HGTs, either from eukaryotes $(82 \%)$ or prokaryotes (18\%). Most of these 98 highly probable HGTs (43\%) show unknown functions and the others, both originating from pro- or eukaryotes, show metabolite functions (based on similarities with protein domains). The absence of detectable eukaryotic HGT in Arabidopsis thaliana, our negative control, suggests that this finding is not an artifact of the method. Using the same approach, previous putative large-scale HGTs have been reported in the available nuclear diatom genomes [36,37], both from bacteria (784 genes in Phaeodactylum tricornutum) or from the green lineage ( $>1,700$ genes). However, although no other 'eukaryotic' potential HGTs are discussed in these papers, orthologous genes shared with other eukaryotic lineages were also described. The presence of green genes in diatoms has been explained by endosymbiotic gene transfers and an alternative hypothesis would be that the presence of stramenopile genes in Bathycoccus may reflect an opposite gene flow from diatom-like cells to Mamiellales. 

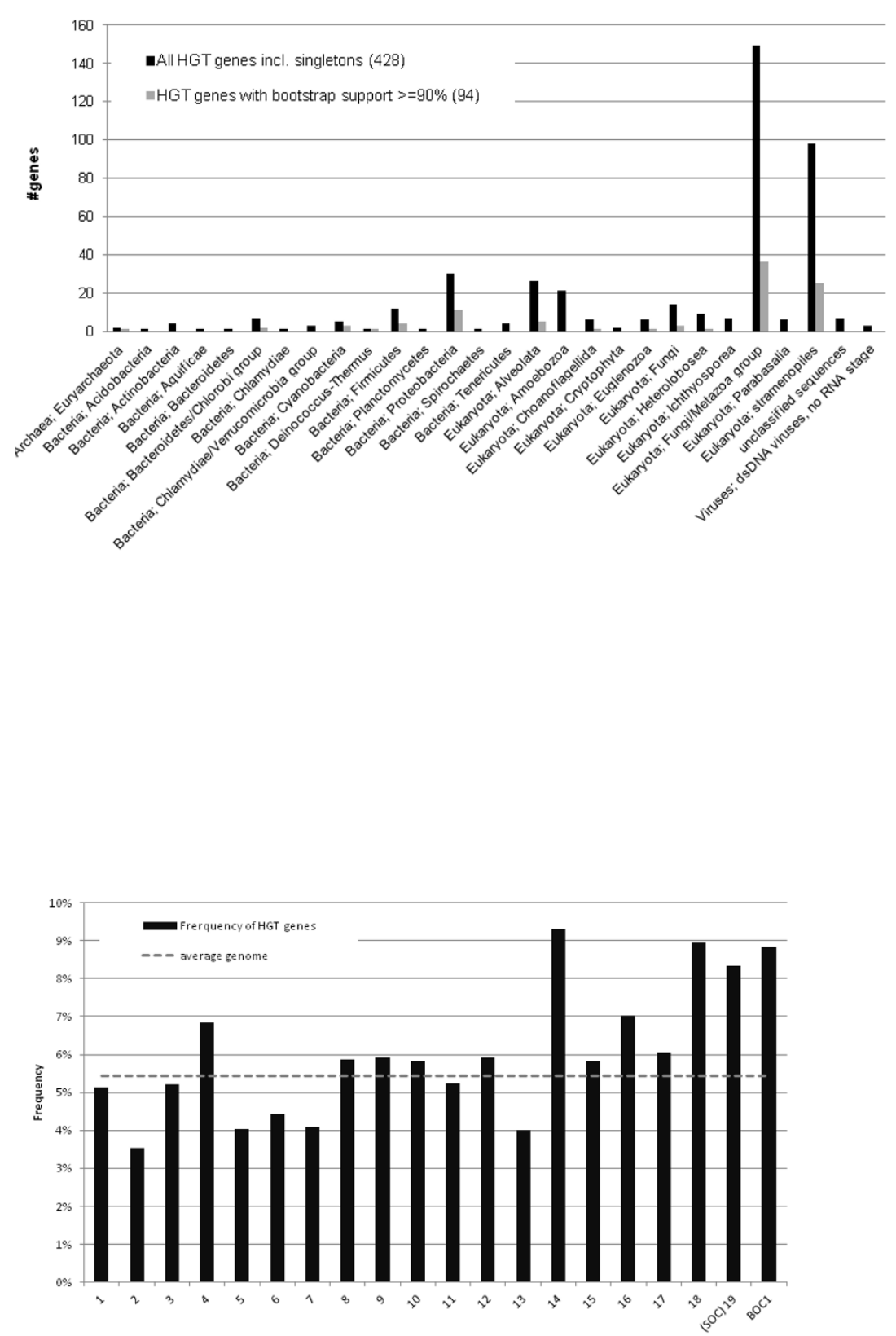

Figure 5 Potential horizontal gene transfer in Bathycoccus. (a) Taxonomic distribution of horizontal gene transfer (HGT) genes identified using BLAST and by phylogenetic analysis of each gene (excluding genes with a multi-kingdom punctuate distribution). Only taxonomic groups including multiple genes are displayed (for a complete overview, see Table S5 in Additional file 1). (b) Frequency of 428 HGT genes over the different chromosomes. The last bin reports the fraction of HGT genes in the BOC1 region (a subset of chromosome 14).

This hypothesis seems unlikely, however, because most of the stramenopile genes found in Bathycoccus are specific to this species and are not found in other Mamilelalles genomes. Alternatively, this mosaic gene repertoire could be the consequence of (i) parallel or convergent molecular evolution or (ii) the evolution through gene loss of a large ancestral genome, with massive and selective gene losses in all Mamiellales descendants, concurrent with genome reduction. However, this scenario is less parsimonious compared to HGT and, again, seems unlikely because of the phylogenetic breadth of the selectively retained genes (bacterial and from different supergroups of the eukaryotic tree of life).

In line with a recent report about the acquisition of ice-binding proteins in sea ice diatoms from prokaryotic origin [38], it is tempting to speculate that the HGT 
genes contribute new functional properties to the Bathycoccus genome. The analysis of a large DNA virus in Ostreococcus tauri suggested that the capture of host DNA in viral genomes could represent a mechanism for the transfer of genes between eukaryotic cells [39]. This idea was confirmed by the additional sequencing of four double-stranded DNA marine prasinovirus genomes (infecting Bathycoccus, Micromonas, and Ostreococcus), showing that these viruses encode a gene repertoire of certain amino acid biosynthesis pathways never previously observed in viruses that are likely to have been acquired from lateral gene transfer from their host or from bacteria [40]. A similar eukaryotic phytoplanktonvirus system was also described in Emiliania huxleyi, mediating the transfer of seven genes related to sphingolipid biosynthesis [41].

To verify whether specific genomic regions or chromosomes would be more likely to harbor genes arriving via HGT, we estimated the number of HGT genes per chromosome. We observed that transferred genes were more or less equally distributed over the different chromosomes, except for the low GC outlier chromosomes, which contained higher fractions of HGT genes (BOC1 and SOC contain 1.63 and 1.54 times more HGT genes compared to the genome-wide average; Figure $5 \mathrm{~b}$ ). Different possibilities for the increased abundance of HGT on the outliers include, for example: (1) they may have specific sequence features that can serve to integrate HGT genes that are subsequently re-arranged and embedded in other locations in the genome; (2) it may reflect a lower density of essential gene functionalities in outliers, which could thus support a higher density of random insertions; or (3) there might be a lower level of recombination on these chromosomes, reducing the rate of removal of deleterious alleles via sexual recombination. None of these scenarios are mutually exclusive.

In the Bathycoccus genome, the gene copy number is highly expanded for four specific gene families, phenomena not found (or at very low copy number expansion) in other Mamiellales or other algae (Table 3). Of these, two are involved in the metabolism of sialic acids, that is, sialyltransferases (69 gene copies) and sialidases (23 gene copies), the two others being ankyrin-repeat proteins (149 gene copies) and zinc finger proteins (48 gene copies) (Table 3). Among these 289 gene copies, 105 (36\%) are represented within the 428 probable genes acquired by HGT, representing $24 \%$ of them.

\section{Sialic acid metabolism in Bathycoccus}

The two enzyme families involved in the metabolism of sialic acids are not present in other known green algae genomes, and both gene families are dispersed all along the Bathycoccus genome without evident clustering or tandem duplication. Although, on average, $15 \%$ of the genes have introns in Bathycoccus, no introns (except three genes; Figure S11 in Additional file 1) were found in any gene from both families. Genes annotated as sialyltransferases correspond to glycosyltransferases family 29 in the CAZy classification, which comprises enzymes able to transfer sialic residues during glycosylation of proteins or lipids [42]. All the Bathycoccus sialyltransferases showed a metazoan taxonic affiliation and none of them gave significant hits with bacteria. These enzymes are type II single pass membrane proteins

Table 3 Expanded gene families in the Bathycoccus genome

\begin{tabular}{|c|c|c|c|c|c|c|}
\hline Gene family ${ }^{a}$ & $\begin{array}{l}\text { Copy number in } \\
\text { Bathycoccus } \\
\text { prasinos }\end{array}$ & $\begin{array}{l}\text { Copy number in } \\
\text { Micromonas sp. } \\
\text { CCMP1545 }\end{array}$ & $\begin{array}{l}\text { Copy number in } \\
\text { Micromonas sp. } \\
\text { RCC299 }\end{array}$ & $\begin{array}{l}\text { Copy number in } \\
\text { Ostreococcus } \\
\text { lucimarinus }\end{array}$ & $\begin{array}{c}\text { Copy number in } \\
\text { Ostreococcus sp. } \\
\text { RCC } 809\end{array}$ & $\begin{array}{c}\text { Copy number } \\
\text { in Ostreococcus } \\
\text { tauri }\end{array}$ \\
\hline $\begin{array}{l}\text { Glycosyl } \\
\text { transferase, family } \\
29 \text { (IPR001675) }\end{array}$ & 78 & 0 & 1 & 0 & 2 & 0 \\
\hline HOM000519 & 43 & 0 & 0 & 0 & 0 & 0 \\
\hline HOM002813 & 10 & 0 & 0 & 0 & 0 & 0 \\
\hline HOM005062 & 10 & 0 & 0 & 0 & 0 & 0 \\
\hline HOM007941 & 6 & 0 & 0 & 0 & 0 & 0 \\
\hline $\begin{array}{l}\text { Ankyrin repeats } \\
\text { (IPR020683) }\end{array}$ & 186 & 124 & 107 & 74 & 55 & 67 \\
\hline HOM000035 & 149 & 56 & 9 & 17 & 6 & 6 \\
\hline $\begin{array}{l}\text { Sialidase/ } \\
\text { neuraminidase } \\
\text { (IPR011040) }\end{array}$ & 23 & 1 & 0 & 0 & 0 & 0 \\
\hline HOM002557 & 17 & 0 & 0 & 0 & 0 & 0 \\
\hline HOM005056 & 5 & 0 & 0 & 0 & 0 & 0 \\
\hline Zinc finger, $\mathrm{C} 2 \mathrm{H} 2$ & 53 & 29 & 35 & 19 & 3 & 17 \\
\hline HOM000293 & 48 & 5 & 4 & 1 & 1 & 1 \\
\hline
\end{tabular}

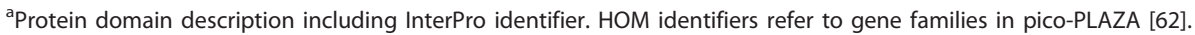


usually known to be anchored in the Golgi membranes $[43,44]$. A potential hydrophobic transmembrane domain was detected on the amino-terminal extremities of all the Bathycoccus sialyltransferases (Figure 6a). For almost all the 69 genes (only 19 are known in human), the sialyltransferase domain is located in the carboxy-terminal part of the protein, whereas the amino-terminal domain is composed of a highly variable stem region (Figure 6a). Although the existence of complete and active sialyltransferases in plants is still a matter of debate [45], all four metazoan consensus motifs were found in the Bathycoccus genes.

The second gene family includes sialidases (or neuraminidases), which are enzymes cleaving the terminal sialic acid residues from glycoproteins or glycolipids. Again, this gene expansion is specific to Bathycoccus. In contrast to the previous family, no clear domain organization could be defined in sialidases, but some key amino acids known to be involved in the catalytic activity are conserved in the Bathycoccus family. The taxonomic origin of the sialidases is less clear than that for the sialyltransferases discussed above, and could correspond to either metazoans or bacteria. For sialidases, scores are globally weak and best blast hits are found mostly with hypothetical proteins either from the choanoflagellate Monosiga brevicolis or from the green alga Chlorella variabilis (where only one sialidase has been annotated).
The expansion of these two enzyme families prompted us to look for specific potential 'sialic acid' metabolism in Bathycoccus. The composition of flagellar scales in Scherffelia dubia (phylum Chlorophyta, class Chlorodendrophyceae) was found to be a mix of acidic polysaccharides having similar structures to sialic acids [46]. Although the chemical nature of the scales covering the Bathycoccus cell membrane is unknown, it is tempting to establish a correlation between the potential biosynthetic pathway of these scales and the expansion of gene families involved in the metabolism of sialic acids. Furthermore, we confirmed previous electron microscopy studies [8,47] showing that, in Bathycoccus as in other Mamiellophyceae, scale biosynthesis occurs inside intracellular vesicles with striking resemblance to Golgi vesicles (Figure 6b-d); that is, in agreement with the notion that they might be produced by sialyltransferases located at the luminal side of intracellular vesicles. Scales almost identical to those of $B$. prasinos are observed in the more closely related Mantoniella squamata [48], where they are also extruded to the surface after transport via the Golgi body [49-51].

\section{Other Bathycoccus expanded gene families}

One of the two other highly expanded gene families in the Bathycoccus genome are ankyrin-repeat proteins (149 gene copies). This family is also expanded, although to a

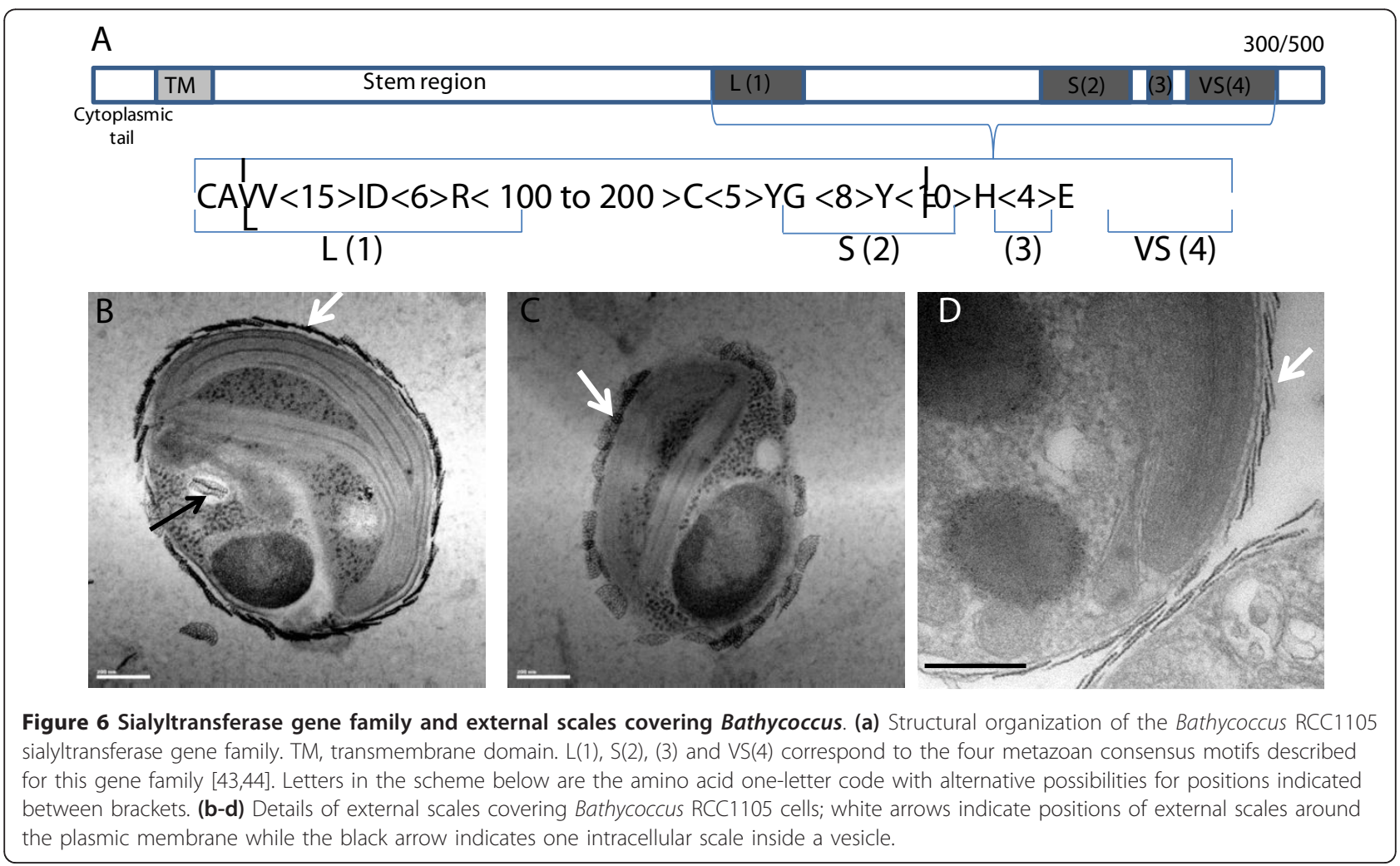


lesser extent, in the Micromonas strain CCMP1545 (56 copies), whereas only very few copies were detected in other Mamiellales (Table 3). These genes have ankyrin repeats located in the carboxy-terminal part of the protein whereas the amino-terminal part has no hit in GenBank. There are also many other ankyrin repeats containing genes in Bathycoccus as in both plants and microalgae, but associated with different protein domains that often have predicted functionalities. Indeed, the ankyrin repeat is considered as one of the most common protein-protein interaction motifs in nature [52]. The 149 Bathycoccus-specific genes were not distributed randomly among chromosomes, with the bigger chromosomes having few copies, whereas chromosomes 12 or 19 bear many tandem duplicated genes (Figure S12 in Additional file 1). No obvious function can be attributed to these genes. However, by analogy with the human membrane-associated ankyrin, which is responsible for the attachment of the cytoskeleton to the plasma membrane, it is possible that a number of these genes might function in some way to bind extracellular scales to the plasmic membrane, although experimental evidence is lacking. It has been shown, however, by electron microscopy coupled to immunogold that scales in Scherffelia dubia are linked to the membrane by glycoproteins [46]. In addition, in Tetraselmis striata (Chlorodendrophyceae) some scale-associated glycoproteins may provide connections between scales and the underlying flagellar membrane [50].

The last group of expanded genes in Bathycoccus are zinc finger proteins. There are many zinc finger proteins in microalgae and in plants, but the family specifically expanded in Bathycoccus is most related to the $\mathrm{C}_{2} \mathrm{H}_{2}$-type zinc finger DNA-binding domain of certain integrases, which share a common alpha/beta two-layer sandwich core structure. The typical organization of the 48 copies identified in the Bathycoccus genome (Table 3) includes a short amino-terminal part (around 20 to 40 amino acids) followed by a strongly acidic region (10 to 20 amino acids) and by 2 to $6 \mathrm{C}_{2} \mathrm{H}_{2}$ domains. Zinc finger proteins were originally identified as DNA-binding domains, although a growing body of evidence suggests an important and widespread role for these domains in protein binding. There are even examples of zinc fingers that support both DNA and protein interactions, and, globally, $\mathrm{C}_{2} \mathrm{H}_{2}$ protein-protein interactions are proving to be more abundant than previously appreciated [53].

The most parsimonious explanation for the abundance of the four expanded gene families would be an initial single HGT event followed by expansion in the Bathycoccus genome. The potential function of these four gene families and their expansion only in Bathycoccus also suggest that they could all be involved in the biosynthesis, exportation and fixation of the scales around the external membrane, and possibly for protection of the cell. Several other members of the Mamiellales have morphologically similar scales around the cells, but they are absent in the two genera Micromonas and Ostreococcus. The most parsimonious evolutionary scenario to explain these observations is that the scale synthesis pathway was acquired by the ancestor of the Mamiellales (or even before) and has been lost in the two naked genera. This scenario predicts that similar gene family expansions should be found in the genomes of other scaled Mamiellaophyceae but not in Micromonas and Ostreococcus. This is the case for Micromonas and Ostreococcus, but the genome sequences of other scaled species are not yet available.

\section{Conclusions}

Mamiellophyceae, and more particularly the three genera Bathycoccus, Micromonas and Ostreococcus, are dominant in different marine areas, where they can play an important role in the primary biomass production. However, the ecological importance of Bathycoccus has probably been overlooked these past years, although it was sporadically mentioned in several studies [5,16-18]. The availability of this genome, coupled to the development of new sequencing possibilities for metagenomes $[19,20]$ from various marine environments, opens the door to future comparative studies and to a better understanding of the adaptations of the organisms to their environment.

\section{Materials and methods \\ B. prasinos RCC1105 genome and EST sequencing and annotation}

The sequenced strain B. prasinos $\mathrm{RCC} 1105$ was isolated in the bay of Banyuls sur mer at the SOLA station (Additional file 1). The genomic DNA was extracted from cell pellets containing a collective total of $6.4 \times 10^{10}$ cells, using a cetyl trimethyl ammonium bromide protocol (adapted from [54]). The Bathycoccus genome was sequenced using Sanger technology on three independent shot-gun libraries with insert sizes of 3 (TKOAAA, vector pcdna2.1 (BstXI)), 10 (TK0AAB, vector pCNS (BstXI)) and $50 \mathrm{~kb}$ (TK0ACA, vector pBeloBAC11 (HindIII) and TK0ACB, vector pBeloBAC11 (BamHI)), resulting in 230,496 reads $(180 \mathrm{Mb}), 118,070$ reads $(152 \mathrm{Mb})$ and 10,368 reads $(14 \mathrm{Mb})$, respectively. After trimming, read numbers were 223,577 reads $(174 \mathrm{Mb})$ for the $3 \mathrm{~kb}$ library, 112,842 reads $(145 \mathrm{Mb})$ for the $10 \mathrm{~kb}$ library and 8,189 reads $(11 \mathrm{Mb})$ for the $50 \mathrm{~kb}$ library, and represented a coverage of 22-fold from $330 \mathrm{Mb}$ of sequenced DNA. The data were assembled using the Genoscope pipe-line that includes the software Arachne 3.0 [55]. ESTs were sequenced from a Bathycoccus culture grown to log phase $\left(10^{7}\right.$ cells $\left./ \mathrm{ml}\right)$, harvested by centrifugation and the cell 
pellets were immediately flash frozen in liquid nitrogen. The total RNA was extracted using the TriReagent (Sigma-Aldrich, Saint-Quentin, France) protocol and mRNAs purified using Poly(A)Purist (Ambion-Applied Bioystems, Saint Aubin, France). Complementary DNAs were constructed and cloned using the CloneMiner procedure (InvitroGen, Saint Aubin, France) with some minor modifications. EST sequences were obtained using pyrosequencing technology developed by Roche (Boulogne-Billancourt, France). A total of 253,791 EST reads were processed through the Genoscope EST pipeline. Short ( $<60 \mathrm{bp}$ ) and low complexity sequences were identified and removed. Clustering and assembly of all 251,875 filtered EST reads resulted in 8,370 EST consensus sequences.

The genome was annotated using the EuGene [56,57] gene finding system with Splice- Machine [58] signal sensor components trained specifically on Bathycoccus datasets. The functional annotation resulted from the synthesis of InterPro and the BLASTP hits against the non-redundant UniProt database. Gene Ontology assignments were derived from the InterPro results. Gene Ontology enrichment analysis was performed using the hypergeometric distribution with Bonferonni correction for multiple hypothesis testing and corrected $P$-values $<0.05$ were retained as significant. The resulting database is publicly available at [59] in a format that includes browse and query options and the genome has been submitted to GenBank.

\section{Comparative sequence and expression analysis}

Starting from all protein-coding genes from the included species (Table 1), only retaining the longest transcript if alternative splicing variants exist, protein sequences were used to construct gene families by applying sequence-based protein clustering. First, an all against all sequence comparison was performed using BLASTP, applying an E-value threshold of $1 \mathrm{e}-05$ and retaining the best 500 hits [60]. Next, the complete sequence similarity graph was processed using Tribe-MCL (mclblastline, default parameters except $\mathrm{I}=2$ and scheme $=4$ ) to identify gene families. A set of 154 single-copy core gene families was used to construct the phylogenetic tree depicted in Figure S1 in Additional file 1 (see also Additional files 2 and 3).

The boundaries of all Mamiellales BOC1 regions were manually delineated based on gene coordinates, gene family information and GC content (Table S2 in Additional file 1). For non-Mamiellales, a 'virtual' BOC1 region was created by taking the best BLASTP hit for each B. prasinos RCC1105 BOC1 gene. Putative BOC1 Mamiellales core gene families (Figure 6, blue lines) were identified by first retaining only those families that contain at least one protein for each Mamiellales species. Next, each family was aligned and manually curated. This was done by inspecting and correcting, if necessary, the structural and functional annotation (NCBI BLAST results plus InterProScan) of all cluster members. For Ostreococcus sp. RCC809 no SOC could be identified in the current draft genome assembly (Additional file 1).

\section{Comparative genomics}

To detect co-linearity within and between species, i-ADHoRe 3.0 was used (Additional file 1) [61] and all chromosomes from all species were compared against each other and significant colinear regions were identified. All gene colinearity can be browsed using the picoPLAZA comparative genomics platform [62]. i-ADHoRe was run with the following settings: alignment_method gg, gap_size 30, cluster_gap 35, q_value 0.9, prob_cutoff 0.0001 , anchor_points 5 and level_2_only false.

EST databases were retrieved from their respective public repositories and mapped on the Mamiellales genomes using GenomeThreader [63] with a minimum alignment score threshold of 0.95 and minimum transcript coverage of 0.89 . Only uniquely mapped ESTs were retained and assigned to genes. When an EST with no strand information overlapped with two adjacent genes, it was assigned to the gene with the highest overlap. For the BOC expression analysis global gene, EST counts were first summarized per functional category. In a second stage, expression enrichment was determined by comparing for each functional category the fraction of BOC expressed genes against the overall fraction of BOC expressed genes (denoted 'relative BOC expression enrichment' in Figure S8 in Additional file 1).

\section{Analysis of potential horizontal gene transfer}

For each protein-coding gene a BLAST sequence similarity search was performed against the NCBI protein database, which contains the proteins of all sequenced Ostreococcus, Micromonas and Chlamydomonas species (E-value <1e-05). Starting from a selection of BLAST hits a phylogenetic approach was used to identify the putative origin of all genes. Briefly, good hits (20\% top hits relative to the best Bit score excluding query self-hits) were retained per gene, protein sequences and detailed taxonomic information was retrieved, a multiple sequence alignment was generated using MUSCLE and a maximum likelihood phylogenetic tree was constructed using PhyML (100 bootstrap sets, WAG model, kappa estimated, 4 substitution rate categories, gamma distribution parameter estimated, BIONJ starting tree, no topology, branch lengths and rate parameter optimization). For each query gene the corresponding tree topology was investigated to identify the nearest neighbor gene/clade, including bootstrap support, and determine the nearest 
neighbor taxonomic information. Genes showing complex punctuate patterns [64] (that is, clustering with homologs from different phyla outside the Viridiplantae; labeled 'multi-kingdom' in Table S5 in Additional file 1) were excluded. Singletons refer to genes for which no phylogenetic analysis could be done because they only have a single BLAST hit based on the $20 \%$ top hits. Nearest neighbors with bootstrap support $>90 \%$ and gene coverage of $50 \%$ or more in the multiple alignment were scored as reliable HGT genes to estimate the fraction of eukaryotic origin. Although the low number of HGT genes found in Arabidopsis does not serve as a perfect negative control for the detection of HGT in unicellular green algae, it suggests that, when applied to a full set of proteins of a specific organism, this approach gives a conservative estimate of putative transfer events with a low number of false positives. To verify if, for some HGT genes, homologous genes exist in other algae that were missed during the process of gene annotation, a systematic sequence similarity search (using tblastn, E-value threshold $1 \mathrm{e}^{-05}$ against intergenic sequences of $O$. tauri, O. lucimarinus, Ostreococcus RCC809, M. pusilla and C. reinhardtii) revealed that, on average, no homologous locus could be found for $93 \%$ of the HGT genes. A list of all HGT genes together with protein alignment and phylogenetic tree statistics is available in Additional file 5.

\section{C-hunter analysis}

Four functional categories (two types with two subdivisions each) were defined and genes were assigned to each class, if applicable. The first type of functional category describes the expression state of a gene (based on uniquely mapped ESTs; is a gene expressed (number of ESTs $>0$ ) or highly expressed (number of ESTs $>2$ )) while the second type describes the intron content of a gene (contains an intron (number of introns $>0$ ) or contains a 'lot' of introns (number of introns $>2$ )). C-hunter [65] software was used to identify, in all genomes, significant clusters of genes belonging to one of the four functional categories. The C-hunter thresholds for each category subdivision were determined by reviewing the average expression and intron content of all Mamiellales genes. C-hunter was run with the following parameters: $<$ C-hunter categories.go genome.index genome.go 280 $800.00150 \mathrm{~T}$ chunter output>.

\section{Accession numbers}

Sequence data from this article (the genome of B. prasinos $\mathrm{RCC} 1105)$ can be found in the EMBL/GenBank data libraries under accession number [FO082258] (mitochondrion), [FO082259] (chloroplast), [FO082278] (chromosome 1), [FO082277] (chromosome 2), [FO082276] (chromosome 3), [FO082275] (chromosome 4), [FO082274] (chromosome 5), [FO082273] (chromosome
6), [FO082272] (chromosome 7), [FO082271] (chromosome 8), [FO082270] (chromosome 9), [FO082269] (chromosome 10), [FO082268] (chromosome 11), [FO082267] (chromosome 12), [FO082266] (chromosome 13), [FO082265] (chromosome 14), [FO082264] (chromosome 15), [FO082263] (chromosome 16), [FO082262] (chromosome 17), [FO082261] (chromosome 18), [FO082260] (chromosome19). The annotation of the genome can be found at the BOGAS web site [66]. EST data are available at the ENA database (accession number ERA148021) and raw genome sequencing data are available at the Trace archive database of the NCBI under the query: species_co$\mathrm{de}=$ "BATHYCOCCUS SP. BAN7".

\section{Additional material}

Additional file 1: Supplementary materials and methods, figures and tables.

Additional file 2: The 154 single-copy core gene families in the green plant lineage.

Additional file 3: Alignment of 154 single-copy core gene families in the green plant lineage.

Additional file 4: Statistics of the genome shotgun sequencing

Additional file 5: Details of maximum likelihood phylogenetic trees describing $B$. prasinos RCC1105 HGT genes.

\section{Abbreviations}

BOC: big outlier chromosome; bp: base pair; CCMP: Center for Culture of Marine Phytoplankton; EST: expressed sequence tag; HGT: horizontal gene transfer; NCBI: National Center for Biotechnology Information; RCC: Roscoff Culture Collection; SOC: small outlier chromosome.

\section{Acknowledgements}

We are very grateful to L Fibla and L Subirana for technical help, R Cooke and M Laudié for sequencing and S Proost for technical assistance during the colinearity analysis. Sequencing of the Bathycoccus genome has been supported by the Genoscope (Evry, France) and this research was supported by the CNRS and the University Pierre et Marie Curie (UMR 7232) and the Agence Nationale de la Recherche grants PHYTADAPT n NT09_567009 and Tara-Girus 09-PCS-GENM-218. We thank Igor Grigoriev, Brian Palenik and the Joint Genome Institute for the access to the Ostreococcus strain RCC809 genome. BV, KV and YVdP acknowledge the support of Ghent University (Multidisciplinary Research Partnership 'Bioinformatics: from nucleotides to networks') and the Interuniversity Attraction Poles Programme (IUAP P6/25), initiated by the Belgian State, Science Policy Office (BioMaGNet).

\section{Author details}

${ }^{1}$ CNRS, UMR 7232, Observatoire Océanologique, Banyuls-sur-Mer, France. UPMC Univ Paris 06, UMR 7232, Observatoire Océanologique, Banyuls-surMer, France. ${ }^{3}$ Department of Plant Systems Biology, VIB, Technologiepark 927, B-9052 Ghent, Belgium. ${ }^{4}$ Department of Plant Biotechnology and Bioinformatics, Ghent University, Technologiepark 927, B-9052 Ghent, Belgium. ${ }^{5}$ Genoscope, CEA, Institut de Génomique, 2 rue Gaston Crémieux CP5706, 91057 Evry cedex, France. ${ }^{6}$ Department of Biotechnology, Norwegian University of Science and Technology (NTNU), 7491 Trondheim, Norway ${ }^{\dagger}$ These two authors contributed equally to this work.

\section{Authors' contributions}

All authors have read and approved the manuscript for publication. ED, $\mathrm{H}$ $M M F, J P, M K, C D S$, and AC performed research and sequencing. HM, BV, SR, $M V B, G P, P R$, and KV analyzed the data and wrote the paper. NG, PW, and YVdP wrote the paper. HM and KV designed the research. 


\section{Competing interests}

The authors declare that they have no competing interests.

Received: 11 April 2012 Revised: 15 August 2012

Accepted: 24 August 2012 Published: 24 August 2012

\section{References}

1. Field BC, Behrenfeld MJ, Randerson JT, Falkowski P: Primary production of the biosphere: integrating terrestrial and oceanic components. Science 1998, 281:237-240

2. Boyce DG, Lewis MR, Worm B: Global phytoplankton decline over the past century. Nature 2010, 466:591-596.

3. Li WKW: Primary productivity of prochlorophytes cyanobacteria, and eucaryotic ultraphytoplankton: measurements from flow cytometric sorting. Limnol Oceanogr 1994, 39:169-175.

4. Worden AZ, Nolan JK, Palenik B: Assessing the dynamics and ecology of marine picophytoplankton: the importance of the eukaryotic component. Limnol Oceanogr 2004, 49:168-179.

5. Knight-Jones EW, Walne PR: Chromulina pusilla Butcher; a dominant member of the ultraplankton. Nature 1951, 167:445.

6. Courties C, Vaquer A, Trousselier M, Lautier J, Chrétiennot-Dinet MJ, Neveux J, Machado MC, Claustre H: Smallest eukaryotic organism. Nature 1994, 370:255.

7. Chrétiennot-Dinet MJ, Courties C, Vaquer A, Neveux J, Claustre H, Lautier J, Machado MC: A new marine picoeukaryote Ostreococcus tauri gen et sp. nov (Chlorophyta, Prasinophyceae). Phycologia 1995, 4:285-292.

8. Eikrem W, Throndsen J: The ultrastructure of Bathycoccus gen nov and $B$. prasinos sp Nov, a non-motile picoplanktonic alga (Chlorophyta, Prasinophyceae) from the Mediterranean and Atlantic. Phycologia 1990, 29:344-350.

9. Worden AZ, Lee JH, Mock T, Rouzé P, Simmons MP, Aerts AL, Allen AE, Cuvelier ML, Derelle E, Everett MV, Foulon E, Grimwood J, Gundlach H, Henrissat B, Napoli C, McDonald SM, Parker MS, Rombauts S, Salamov A, Von Dassow P, Badger JH, Coutinho PM, Demir E, Dubchak I, Gentemann C, Eikrem W, Gready JE, John U, Lanier W, Lindquist EA, Lucas S, et al: Green evolution and dynamic adaptations revealed by genomes of the marine picoeukaryotes Micromonas. Science 2009, 324:268-272.

10. Derelle E, Ferraz C, Rombauts S, Rouzé P, Worden AZ, Robbens S, Partensky F, Degroeve S, Echeynié S, Cooke R, Saeys Y, Wuyts J, Jabbari K, Bowler C, Panaud O, Piégu B, Ball SG, Ral JP, Bouget FY, Piganeau G, De Baets B, Picard A, Delseny M, Demaille J, Van de Peer Y, Moreau H: Genome analysis of the smallest free-living eukaryote Ostreococcus tauri unveils many unique features. Proc Natl Acad Sci USA 2006, 103:11647-11652.

11. Palenik B, Grimwood J, Aerts A, Rouzé P, Salamov A, Putnam N, Dupont C, Jorgensen R, Derelle E, Rombauts S, Zhou K, Otillar R, Merchant SS, Podell S, Gaasterland T, Napoli C, Gendler K, Manuell A, Tai V, Vallon O, Piganeau G, Jancek S, Heijde M, Jabbari K, Bowler C, Lohr M, Robbens S, Werner G, Dubchak I, Pazour GJ, Ren Q, Paulsen I, et al: The tiny eukaryote Ostreococcus provides genomic insights into the paradox of plankton speciation. Proc Natl Acad Sci USA 2007, 104:7705-7710.

12. Guillou L, Eikrem W, Chrétiennot-Dinet MJ, Le Gall F, Massana R, Romari K, Pedrós-Alió C, Vaulot D: Diversity of picoplanktonic prasinophytes assessed by direct nuclear SSU rDNA sequencing of environmental samples and novel isolates retrieved from oceanic and coastal marine ecosystems. Protist 2004, 155:193-214.

13. Marin B, Melkonian M: Molecular phylogeny and classification of the Mamiellophyceae class nov (Chlorophyta) based on sequence comparisons of the nuclear- and plastid-encoded rRNA operons. Protist 2010, 161:304-336

14. Peers GK, Niyogi K: Pond scum genomics: The genomes of Chlamydomonas and Ostreococcus. Plant Cell 2008, 20:502-507.

15. Johnson PW, McSieburth J: In-situ morphology and occurrence of eukaryotic phototrophs of bacterial size in the picoplankton of estuarine and oceanic waters. J Phycol 1982, 18:318-327.

16. Marie D, Zhu F, Balagué V, Ras J, Vaulot D: Eukaryotic picoplankton communities of the Mediterranean Sea in summer assessed by molecular approaches (DGGE, TTGE, QPCR). FEMS Microbiol Ecol 2006, 55:403-415.

17. Monier A, Welsh RM, Gentemann C, Weinstock G, Sodergren E, Armbrust EV, Eisen JA, Worden AZ: Phosphate transporters in marine phytoplankton and their viruses: cross-domain commonalities in viralhost gene exchanges. Environ Microbiol 2011, 14:162-176.

18. Treusch AH, Demir-Hilton E, Vergin KL, Worden AZ, Carlson CA, Donatz MG, Burton RM, Giovannoni SJ: Phytoplankton distribution patterns in the northwestern Sargasso Sea revealed by small subunit rRNA genes from plastids. ISME J 2011, 6:481-492.

19. Cheung MK, Au CH, Chu KH, Kwan HS, Wong CK: Composition and genetic diversity of picoeukaryotes in subtropical coastal waters as revealed by 454 pyrosequencing. ISME J 2010, 4:1053-1059.

20. Marie D, Shi X L, Rigaut-Jalabert F, Vaulot D: Use of flow cytometric sorting to better assess the diversity of small photosynthetic eukaryotes in the English Channel. FEMS Microbiol Ecol 2010, 72:165-178.

21. Massana R, Balagué V, Guillou L, Pedrós-Alió C: Picoeukaryotic diversity in an oligotrophic coastal site studied by molecular and culturing approaches. FEMS Microbiol Ecol 2004, 50:231-243.

22. Haugen PD, Simon D, Bhattacharya D: The natural history of group I introns. Trends Genet 2005, 21:111-119.

23. Piganeau G, Grimsley N, Moreau H: Genome diversity in the smallest marine photosynthetic eukaryotes. Res Microbiol 2011, 162:570-577.

24. Blanc G, Duncan G, Agarkova I, Borodovsky M, Gurnon J, Kuo A, Lindquist E, Lucas S, Pangilinan J, Polle J, Salamov A, Terry A, Yamada T, Dunigan DD, Grigoriev IV, Claverie JM, Van Etten JL: The Chlorella variabilis NC64A genome reveals adaptation to photosymbiosis, coevolution with viruses, and cryptic sex. Plant Cell 2010, 22:2943-2955.

25. Zhang X: The epigenetic landscape of plants. Science 2008, 320:489-492.

26. Wong $S$, Wolfe KH: Birth of a metabolic gene cluster in yeast by adaptive gene relocation. Nat Genet 2005, 37:777-782.

27. Lee SC, Ni M, Li W, Shertz C, Heitman J: The evolution of sex: a perspective from the fungal kingdom. Microbiol Mol Biol Rev 2010, 74:298-340.

28. Soo Chan Lee SC, Ni M, Li W, Shertz C, Heitman J: The evolution of sex: a perspective from the fungal kingdom. Microbiol Mol Biol Rev 2010, 74:298-340.

29. Jancek S, Gourbiere S, Moreau H, Piganeau G: Clues about the genetic basis of adaptation emerge from comparing the proteomes of two Ostreococcus ecotypes (Chlorophyta, Prasinophyceae). Mol Biol Evol 2008, 25:2293-2300.

30. Avrani S, Wurtzel O, Sharon I, Sorek R, Lindell D: Genomic island variability facilitates Prochlorococcus-virus coexistence. Nature 2011, 474:604-608.

31. Bellec L, Grimsley N, Derelle E, Moreau H, Desdevises Y: Abundance, spatial distribution and genetic diversity of Ostreococcus tauri viruses in two different environments. Env Microbiol Reports 2010, 2:313-321.

32. Thomas R, Grimsley N, Escande ML, Subirana L, Derelle E, Moreau H: Acquisition and maintenance of resistance to viruses in eukaryotic phytoplankton populations. Env Microbiol 2011, 13:1412-1420.

33. Ragan MA, Harlow TJ, Beiko RG: Do different surrogate methods detect lateral genetic transfer events of different relative ages?. Trends Microbiol 2006, 14:4-8.

34. Kurland CG, Canback B, Berg OG: Horizontal gene transfer: a critical view. Proc Natl Acad Sci USA 2003, 100:9658-9662.

35. Keeling PJ, Palmer JD: Horizontal gene transfer in eukaryotic evolution. Nat Rev Genet 2008, 9:605-618.

36. Bowler C, Allen AE, Badger JH, Grimwood J, Jabbari K, Kuo A, Maheswari U, Martens C, Maumus F, Otillar RP, Rayko E, Salamov A, Vandepoele K, Beszteri B, Gruber A, Heijde M, Katinka M, Mock T, Valentin K, Verret F, Berges JA, Brownlee C, Cadoret JP, Chiovitti A, Choi CJ, Coesel S, De Martino A, Detter JC, Durkin C, Falciatore A, Fournet J, et al: The Phaeodactylum genome reveals the evolutionary history of diatom genomes. Nature 2008, 456:239-244.

37. Moustafa A, Beszteri B, Maier UG, Bowler C, Valentin K, Bhattacharya D: Genomic footprints of a cryptic plastid endosymbiosis in diatoms. Science 2009, 324:1724-1726.

38. Raymond JA, Kim HJ: Possible role of horizontal gene transfer in the colonization of sea ice by algae. PLoS One 2012, 7:e35968.

39. Derelle E, Ferraz C, Escande ML, Eychenie S, Cooke R, Piganeau G, Desdevises Y, Bellec L, Moreau H, Grimsley N: Life-cycle and genome of OtV5, a large DNA virus of the pelagic marine unicellular green alga Ostreococcus tauri. PLoS One 2008, 3:e2250.

40. Moreau H, Piganeau G, Desdevises Y, Cooke R, Derelle E, Grimsley N: Marine prasinovirus genomes show low evolutionary divergence and 
acquisition of protein metabolism genes by horizontal gene transfer. $J$ Virol 2010, 84:12555-12563.

41. Monier A, Pagarete A, de Vargas C, Allen MJ, Read B, Claverie JM, Ogata H: Horizontal gene transfer of an entire metabolic pathway between a eukaryotic alga and its DNA virus. Genome Res 2009, 19:1441-1449.

42. Cantarel BL, Coutinho PM, Rancurel C, Bernard T, Lombard V, Henrissat B: The Carbohydrate-Active EnZymes database (CAZy): an expert resource for Glycogenomics. Nucleic Acids Res 2009, , 37 Database: D233-238.

43. Jeanneau C, Chazalet V, Augé C, Soumpasis DM, Harduin-Lepers A, Delannoy P, Imberty A, Breton C: Structure-function analysis of the human sialyltransferase ST3Gall. J Biol Chem 2004, 279:13461-13468.

44. Harduin-Lepers A, Mollicone R, Delannoy P, Oriol R: The anormal sialyltransferase-related genes: a phylogenetic approach. Glycobiology 2005, 15:805-817.

45. Harduin-Lepers A, Mollicone R, Delannoy P, Oriol R: The animal sialyltransferases and sialyltransferase-related genes: a phylogenetic approach. Glycobiology 2005, 15:805-817, A published erratum appears in Glycobiology 2005, 15:21 G

46. Melkonian M, Preisig HR: A light and electron microscopic study of Scherffelia dubia, a new member of the scaly green flagellates (Prasinophyceae). Nord J Bot 1986, 6:235-256.

47. Moestrup O, Walne PL: Studies on scale morphogenesis in the Golgi apparatus of Pyramimonas tetrarhynchus (Prasinophyceae). J Cell Sci 1979, 36:437-459.

48. Moestrup O: Scale structure in Mantoniella squamata, with some comments on the phylogeny of the Prasinophyceae (Chlorophyta). Phycologia 1990, 29:437-442.

49. Melkonian M, Becker B, Becker D: Scale formation in algae. J Electron Microscopy Technique 1991, 17:165-178.

50. Becker D, Melkonian M: N-linked glycoproteins associated with flagellar scales in a flagellate green alga: characterization of interactions. Eur $J$ Cell Biol 1992, 57:109-116.

51. Becker B: Anterograde transport of algal scales through the Golgi complex is not mediated by vesicles. Trends Cell Biol 1995, 5:305-307.

52. Al-Khodor S, Price CT, Kalia A, Kwaik A: Functional diversity of ankyrin repeats in microbial proteins. Trends Microbiol 2010, 18:132-139.

53. Brayer KJ, Segal DJ: Keep your fingers off my DNA: protein-protein interactions mediated by $\mathrm{C} 2 \mathrm{H} 2$ zinc finger domains. Cell Biochem Biophys 2008, 50:111-131.

54. Winnepenninckx B, Backeljau T, De Wachter R: Extraction of high molecular weight DNA from molluscs. Trends Genet 1993, 9:407.

55. Batzoglou S, Jaffe DB, Stanley K, Butler J, Gnerre S, Mauceli E, Berger B, Mesirov JP, Lander ES: ARACHNE: a whole-genome shotgun assembler. Genome Res 2002, 12:177-189.52.

56. Schiex T, Moisan A, Rouzé P: EUGÉNE: an eukaryotic gene finder that combines several sources of evidence. Lect Notes Comput Sci 2001, 2066:111-125.

57. Foissac S, Gouzy J, Rombauts S, Mathé C, Amselem J, Sterck L, Van de Peer $Y$, Rouzé $P$, Schiex T: Genome annotation in plants and fungi: EuGène as a model platform. Curr Bioinformatics 2008, 3:87-97.

58. Degroeve S, Saeys Y, De Baets B, Rouzé P, Van de Peer Y: SpliceMachine: predicting splice sites from high-dimensional local context representations. Bioinformatics 2005, 21:1332-1338.

59. Genome Sequences and Annotations at Ghent University.. [http:// bioinformatics.psb.ugent.be/genomes].

60. Altschul SF, Madden TL, Schäffer AA, Zhang J, Zhang Z, Miller W, Lipman DJ: Gapped BLAST and PSI-BLAST: a new generation of protein database search programs. Nucleic Acids Res 1997, 25:3389-33402.

61. Proost S, Fostier J, De Witte D, Dhoedt B, Demeester P, Van de Peer $Y$, Vandepoele K: i-ADHoRe 30 - fast and sensitive detection of genomic homology in extremely large data sets. Nucleic Acids Res 2012, 40:e11.

62. pico-PLAZA: an integrative resource for cross-species genome analysis in algae.[http://bioinformatics.psb.ugent.be/pico-plaza/].

63. Gremme G, Brendel V, Sparks ME, Kurtz S: Engineering a software tool for gene structure prediction in higher organisms. Information Software Technol 2005, 47:965-978

64. Rogers MB, Watkins RF, Harper JT, Durnford DG, Gray MW, Keeling PJ: A complex and punctate distribution of three eukaryotic genes derived by lateral gene transfer. BMC Evol Biol 2007, 7:89.

65. Yi G, Sze SH, Thon MR: Identifying clusters of functionally related genes in genomes. Bioinformatics 2007, 23:1053-1060.
66. Bathycoccus Genome Annotation Database at Ghent University.. [http:// bioinformatics.psb.ugent.be/webtools/bogas/].

67. Krzywinski M, Schein J, Birol I, Connors J, Gascoyne R, Horsman D, Jones SJ, Marra MA: Circos: an information aesthetic for comparative genomics. Genome Res 2009, 19:1639-1645.

68. Merchant SS, Prochnik SE, Vallon O, Harris EH, Karpowicz SJ, Witman GB, Terry A, Salamov A, Fritz-Laylin LK, Maréchal-Drouard L, Marshall WF, Qu LH, Nelson DR, Sanderfoot AA, Spalding MH, Kapitonov W, Ren Q, Ferris P, Lindquist E, Shapiro H, Lucas SM, Grimwood J, Schmutz J, Cardol P, Cerutti H, Chanfreau G, Chen CL, Cognat V, Croft MT, Dent R, Dutcher S, et al: The Chlamydomonas genome reveals the evolution of key animal and plant functions. Science 2007, 318:245-250.

69. Prochnik SE, Umen J, Nedelcu AM, Hallmann A, Miller SM, Nishii I, Ferris P, Kuo A, Mitros T, Fritz-Laylin LK, Hellsten U, Chapman J, Simakov O, Rensing SA, Terry A, Pangilinan J, Kapitonov V, Jurka J, Salamov A, Shapiro H, Schmutz J, Grimwood J, Lindquist E, Lucas S, Grigoriev IV, Schmitt R, Kirk D, Rokhsar DS: Genomic analysis of organismal complexity in the multicellular green alga Volvox carteri. Science 2010, 329:223-226.

doi:10.1186/gb-2012-13-8-r74

Cite this article as: Moreau et al:: Gene functionalities and genome structure in Bathycoccus prasinos reflect cellular specializations at the base of the green lineage. Genome Biology 2012 13:R74.

\section{Submit your next manuscript to BioMed Central and take full advantage of:}

- Convenient online submission

- Thorough peer review

- No space constraints or color figure charges

- Immediate publication on acceptance

- Inclusion in PubMed, CAS, Scopus and Google Scholar

- Research which is freely available for redistribution

Submit your manuscript at www.biomedcentral.com/submit
Biomed Central 